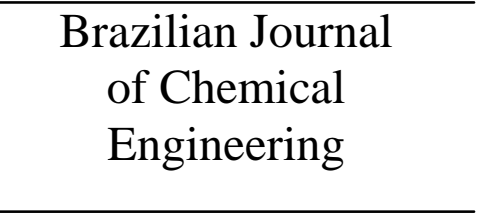

ISSN 0104-6632

Printed in Brazil

www.abeq.org.br/bjche

Vol. 23, No. 02, pp. 251 - 258, April - June, 2006

\title{
SUPERCRITICAL CARBON DIOXIDE EXTRACTION OF PIGMENTS FROM Bixa orellana SEEDS (EXPERIMENTS AND MODELING)
}

\author{
B. P. Nobre ${ }^{1}$, R. L. Mendes ${ }^{*}$, E. M. Queiroz ${ }^{2}$, F. L. P. Pessoa ${ }^{2}$, \\ J. P.Coelho ${ }^{3}$ and A. F. Palavra ${ }^{4}$ \\ ${ }^{1}$ INETI, Departamento Energias Renováveis, Estrada do Paço do Lumiar, \\ Phone +351 21-712-7192; fax +351 21-712-7195; 1639-038, Lisboa, Portugal. \\ E-mail: rui.mendes@ineti.pt \\ ${ }^{2}$ UFRJ, Departamento de Engenharia Química, Escola de Química, Rio de Janeiro - RJ, Brazil. \\ ${ }^{3}$ ISEL, Departamento de Engenharia Química, Lisboa, Portugal. \\ ${ }^{4}$ IST, Departamento de Engenharia Química, Lisboa, Portugal.
}

(Received: October 20, 2004 ; Accepted: March 5, 2006)

\begin{abstract}
Supercritical $\mathrm{CO}_{2}$ extraction of the pigments from Bixa orellana seeds was carried out in a flow apparatus at a pressure of 200 bar and a temperature of $40{ }^{\circ} \mathrm{C}$ at two fluid flow rates $(0.67 \mathrm{~g} / \mathrm{min}$ and $1.12 \mathrm{~g} / \mathrm{min}$ ). The efficiency of the extraction was low (only about $1 \%$ of the pigment was extracted). The increase in flow rate led to a decrease in pigment recovery. A large increase in recovery (from $1 \%$ to $45 \%$ ) was achieved using supercritical carbon dioxide with $5 \mathrm{~mol} \%$ ethanol as extraction fluid at pressures of 200 and $300 \mathrm{bar}$ and temperatures of 40 and $60^{\circ} \mathrm{C}$. Although the increase in temperature and pressure led to an increase in recovery, the changes in flow rate did not seem to affect it. Furthermore, two plug flow models were applied to describe the supercritical extraction of the pigments from annatto seeds. Mass transfer coefficients were determined and compared well with those obtained by other researchers with similar models for the supercritical extraction of solutes from plant materials.
\end{abstract}

Keywords: Supercritical carbon dioxide; Bixa orellana seeds.

\section{INTRODUCTION}

Annatto (Bixa orellana) is a tropical tree whose seeds produce pigments with hues from yellow to red. Among other applications, these colours are used in the food industry to improve cheese, margarine and butter. One of the main pigments in the pericarp of the seeds is the carotenoid bixin $\left(\mathrm{C}_{25} \mathrm{H}_{30} \mathrm{O}_{4}\right)$, which is one of the main natural colours (Scotter et al., 1994) and is found only in this plant. Chemically it is the mono-methyl ester of the dicarboxylic acid norbixin, another important pigment found in annatto seeds.

While this compound is soluble in oils upon heating and weakly soluble in supercritical $\mathrm{CO}_{2}$ (Nobre et al., 2002), norbixin is soluble in water and insoluble in supercritical $\mathrm{CO}_{2}$ (Degnan et al., 1991). Commercial extracts of oil-soluble annatto pigments are obtained from the seeds by several processes, such as suspension in oil, mechanical processes and solvent extraction with chloroform, dichloroethane and acetone (Preston and Rickard, 1980).

*To whom correspondence should be addressed 
Thecommercial preparations of annatto colours with organic solvents have the disadvantages of small concentrations of pigments and a residual toxic solvent in the product. Suspensions of annatto pigments in vegetable oil are more concentrated but can contain several degradation products due to the fact that high temperatures $\left(>100^{\circ} \mathrm{C}\right)$ are used in the extraction process (McKeown and Mark, 1962; Reith and Gielen, 1971). Supercritical extraction with $\mathrm{CO}_{2}$ could be a good alternative to avoid these problems (Mendes et al., 2003).

Studies of Annatto pigment extraction have been carried out using supercritical $\mathrm{CO}_{2}$ (Degnan et al., 1991; Chao et al., 1991) and $\mathrm{CO}_{2}$ modified with several entrainers (methanol, chloroform and acetonitrile) (Anderson et al., 1997). It was shown that the entrainers increased the efficiency of extraction.

The objective of this work was to carry out supercritical fluid extraction of pigments from annatto seeds with $\mathrm{CO}_{2}$ and $\mathrm{CO}_{2}$ modified with ethanol and to assess the effects of temperature, pressure and solvent flow rate on the extraction yield and to propose a model to describe supercritical extraction.

\section{MATERIALS AND METHODS}

Carbon dioxide (99.998\% purity) and carbon dioxide modified with $5 \mathrm{~mol} \%$ ethanol were purchased from Air Liquide (Portugal). Annatto seeds and bixin were supplied by Universidade Federal do Rio de Janeiro (Nobre et al., 2002). Chloroform (p.a.), methanol (HPLC grade), acetic acid (p.a) and hexane (p.a) were purchased from Merck.

The pigment content of the seeds was determined by a method using organic extraction (McKeown and Mark, 1962), which consists in repeated extraction of the seeds with chloroform, up to total extraction of the colour. The total pigment content was determined using the Lambert-Beer law, measuring the absorbance of the solution at $501 \mathrm{~nm}$ [absorptivity $282.6 \mathrm{~L} /(\mathrm{g} . \mathrm{cm})]$. Whole seeds and ground seeds were analysed, with similar results for both conditions.

The seed oil content was quantified by gravimetric analysis, evaporating until dry $5 \mathrm{ml}$ portions of the total volume of the organic extraction solution. On the other hand, the bixin concentration in the seeds was determined by analysing by HPLC (see below) the solution obtained with organic extraction of the seeds.

The supercritical measurements were carried out in a flow-type apparatus thoroughly described in a previous paper (Mendes et al., 1995). In this apparatus, the metering pump compresses the liquid solvent to the desired pressure, which is controlled by a back-pressure regulator. In order to guarantee that the fluid reaches the extraction vessel at the desired temperature, the fluid passes through a coil immersed in a temperature-controlled water bath. After passing the seed bed ( $2 \mathrm{~g})$ contained in a $5 \mathrm{cc}$ cylindrical extraction vessel (id: $7.9 \mathrm{~mm}$ ) the fluid is expanded to atmospheric pressure through a threeway valve, and the extract precipitates in the glass wool placed inside the cooled glass U-tube. Gas flow rate is monitored by a rotameter and total volume of gas is measured with a wet test meter.

The extracts were collected by washing the glass wool, the inside of the three-way valve and the expansion tubing with chloroform containing $0.2 \mathrm{wt}$. $\%$ of BHT. The total pigment content was quantified by spectrophotometry. For the supercritical extraction measurements, fractions of 10 to $20 \mathrm{~L}$ of expanded gas were collected during extraction. Two flow rates were tested: $0.67 \mathrm{~g} / \mathrm{min}$ and $1.12 \mathrm{~g} / \mathrm{min}$.

To assess the amount of pigment extracted, UVVisible spectra were run between 300 and $700 \mathrm{~nm}$ and the concentration of pigment was determined using the Lambert-Beer law, measuring the absorbance at $501 \mathrm{~nm}$.

The collected solutions were also analysed by HPLC. The system consisted of a liquid chromatograph, Hewlett Packard 1100 series, with a UV/VIS detector adjusted to $501 \mathrm{~nm}$. A mobile phase of methanol and 2\% acetic acid $(87: 13, \mathrm{v} / \mathrm{v})$ was used at $1 \mathrm{ml} / \mathrm{min}$ with the stationary phase Nova Pak $\mathrm{C}_{18}$ column.

The quantification of the total supercritical extract (oils) for each seed batch was determined by gravimetric analysis, weighing the seeds before and after each experiment.

\section{RESULTS AND DISCUSSION}

Supercritical $\mathrm{CO}_{2}$ extraction of pigments from annatto seeds was carried out at 200 bar and $40{ }^{\circ} \mathrm{C}$. The recoveries obtained were low and decreased with the fluid flow rate (Fig. 1). The concentration of pigments in the extracted oil (about $0.4 \%$ ) was much lower than that obtained using chloroform as extraction solvent.

In Figure 2 the changes in concentration of the pigment during extraction is represented for the lower flow rate, as is the solubility of bixin at 200 bar and $40^{\circ} \mathrm{C}$.

The initial concentration of pigments is much higher than the solubility of bixin at the same 
pressure and temperature. That concentration decreases during extraction until the solubility value of the bixin is reached. The major component of the pigments in the seeds is cis-bixin (about 69 wt. \%). The composition of the pigments in the supercritical extracts was near this value, although for the first fractions collected there was an increase in the concentration of bixin (about 75 wt. \%) for several extraction conditions.

Whole seeds were submitted to extraction with carbon dioxide modified with ethanol at temperatures of $40{ }^{\circ} \mathrm{C}$ and $60{ }^{\circ} \mathrm{C}$, pressures of 200 bar and 300 bar and flow rates of $0.67 \mathrm{~g} / \mathrm{min}$ and $1.12 \mathrm{~g} / \mathrm{min}$. Milled seeds were also submitted to supercritical $\mathrm{CO}_{2}\left(200 \mathrm{bar} / 40{ }^{\circ} \mathrm{C}\right)$. Recovery of the pigments did not increase with milling, possibly due to the location of these compounds at the surface of the seeds.

However, it was verified that this recovery increased with temperature at a constant pressure and with pressure at a constant temperature for the same flow rate (Fig. 3).

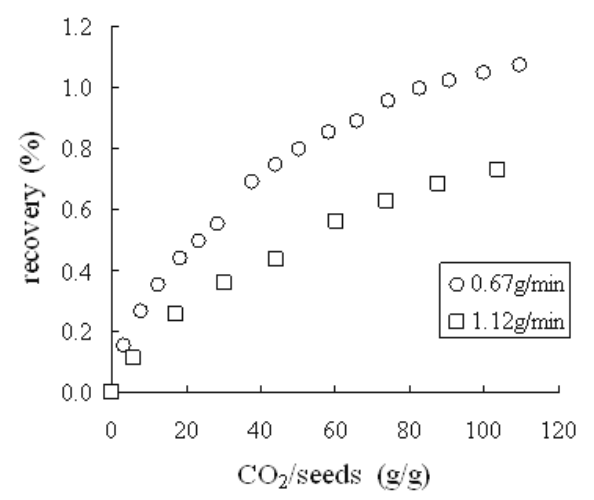

Figure 1: Recovery of pigments from annatto seeds as a function of solvent/seed ratio at $40^{\circ} \mathrm{C}$ and 200 bar for two flow rates.

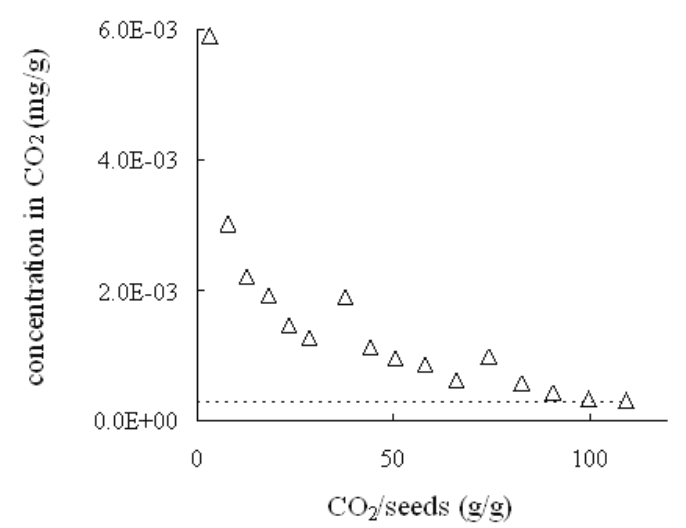

Figure 2: Concentration of pigments as a function of solvent/seed ratio at $200 \mathrm{bar} / 40{ }^{\circ} \mathrm{C}$.

---- Solubility of bixin in $\mathrm{CO}_{\text {, }}$ under these conditions (Nobre et al., 2002).

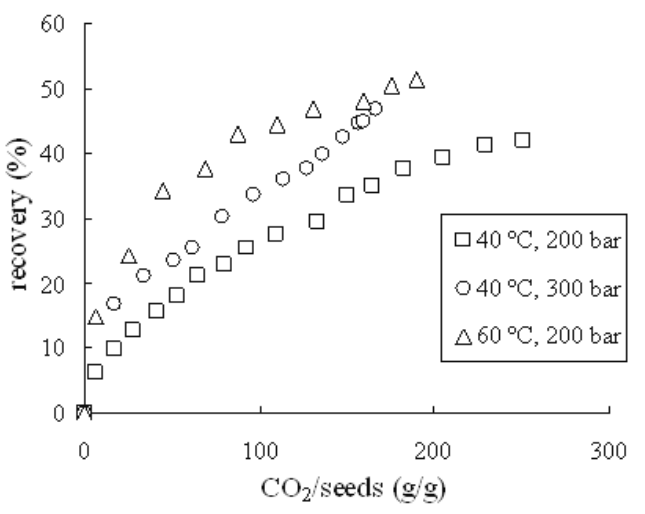

Figure 3: Recovery of pigments from annatto seeds as a function of the solvent/seed ratio of modified $\mathrm{CO}_{2}$. 
In Figure 4 the recovery of pigments by extraction using $\mathrm{CO}_{2}$ plus ethanol is represented. It can be verified that recovery practically does not change with flow rate for a large extent of the extraction (at least up to $30 \%$ of the pigments are obtained). This means that pigment extraction is limited by the equilibrium between the solid and fluid phases with values of concentration near or above the values of the solubility of bixin in this solvent mixture on the initial part of the curve (Fig. 5). This behaviour is quite different from that shown by supercritical extraction using pure $\mathrm{CO}_{2}$ (Fig. 1), in which extraction is limited by the intra-particle resistance to mass transfer. Ethanol can have two effects: one as entrainer, increasing the solubility of the pigments, and the other one as modifier of the mass transfer regime (easing the release of bixin from the seed pericarp).

In Figure 6 the changes in concentration of the pigments (mainly bixin) during extraction at a pressure of $200 \mathrm{bar}$, a temperature of $40{ }^{\circ} \mathrm{C}$ and a flow rate of $0.67 \mathrm{~g} / \mathrm{min}$ is shown. The values are compared with the solubility of bixin in $\mathrm{CO}_{2}$ plus ethanol, at the same pressure and temperature.

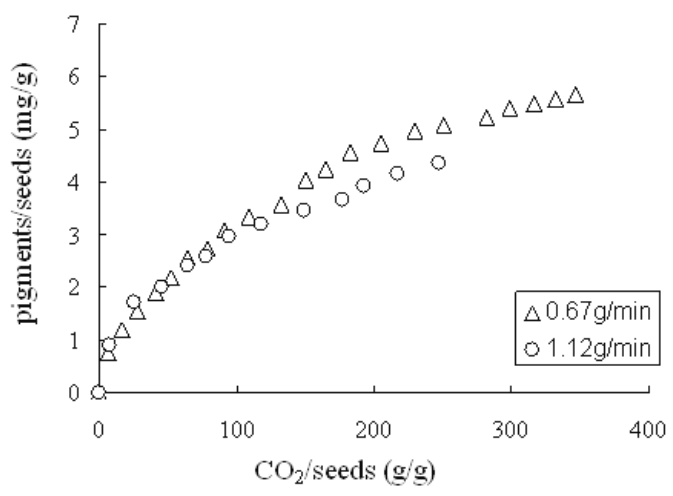

Figure 4: Recovery of pigments from annatto seeds with supercritical $\mathrm{CO}_{2}+$ ethanol (200 bar, $40^{\circ} \mathrm{C}$ ) as a function of solvent/seed ratio for two solvent flow rates.

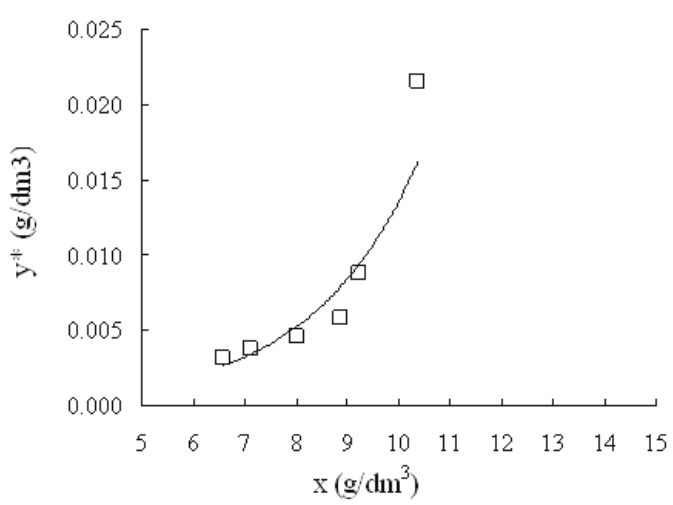

Figure 5: Equilibrium concentration of pigments at the fluid-seed interface as a function of the concentration of pigments in the seeds ( $200 \mathrm{bar}, 40^{\circ} \mathrm{C}$ ).

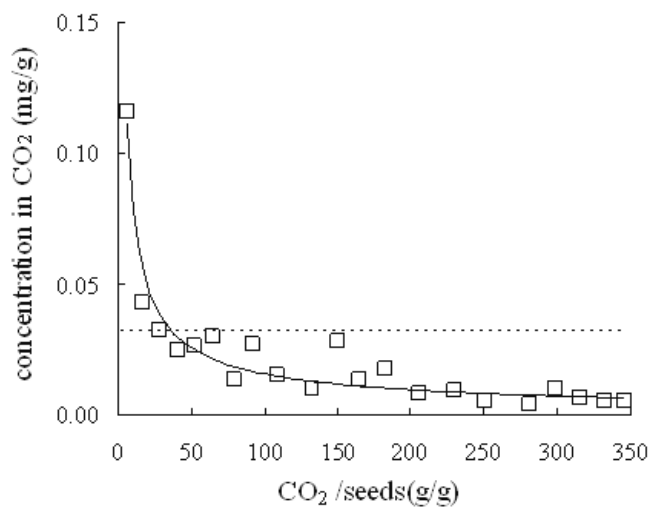

Figure 6: Concentration of pigments from annatto seeds with supercritical $\mathrm{CO}_{2}+$ ethanol as a function of solvent/seed ratio at a pressure of $200 \mathrm{bar}$, a temperature of $40^{\circ} \mathrm{C}$ and a fluid flow rate of $0.67 \mathrm{~g} / \mathrm{min}$. --Solubility of bixin in $\mathrm{CO}_{2}$ plus ethanol (200 bar, $40^{\circ} \mathrm{C}$ ) (Nobre et al., 2003). 
Initially, the concentration is higher than that of bixin, possibly due to the effect of entrainment the triglycerides extracted with the pigments and also to the presence in the seeds of small amounts of degradation products $\left(\mathrm{C}_{17}\right.$ yellow pigment, for instance). There is a short interval in which the values are similar to those for solubility of the compound, and after depletion of part of the bixin from the bed, the concentration decreases monotonously.

The behaviour of the two solvent systems (carbon dioxide, pure or with ethanol) in extracting the pigments (namely bixin) from annatto seeds is different in the recoveries obtained and in the mass transfer mechanisms. But a similar plug flow model (Sovovà, 1994b) can be applied to both situations. Important developments of models to represent supercritical fluid extraction have recently been published. These models deal with the extraction of vegetable oils (Reverchon and Marrone, 2001) and of oil from rosehip seeds (del Valle et al., 2004).

In the present work, it is assumed that the axial dispersion is negligible and that the properties of the solvent and seed bed remain unaltered. It is also assumed that the pigments are a single solute. When recovery is represented against time for extraction with pure $\mathrm{CO}_{2}$, the points fall on a common curve for the two flow rates (Fig. 7). On the contrary, with $\mathrm{CO}_{2}$ plus ethanol, the curve corresponding to the higher flow rate is above that of the lower flow rate (Fig. 8). In the former case (pure $\mathrm{CO}_{2}$ ), it is appropriate to assume that intra-particle resistance to mass transfer controls the extraction. In the latter case $\left(\mathrm{CO}_{2}\right.$ plus ethanol), it is also appropriate to assume that the solvent film controls extraction. In both models, overall mass transfer coefficients are determined, an internal one for the extraction with pure $\mathrm{CO}_{2}$ and an external one for the system with ethanol.

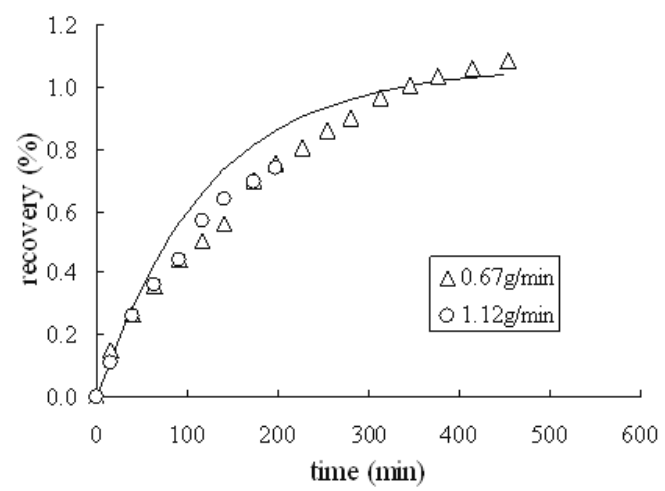

Figure 7: Recovery of pigments in supercritical $\mathrm{CO}_{2}$ extraction at 200 bar and $40{ }^{\circ} \mathrm{C}$ as a function of time at two flow rates. - Model.

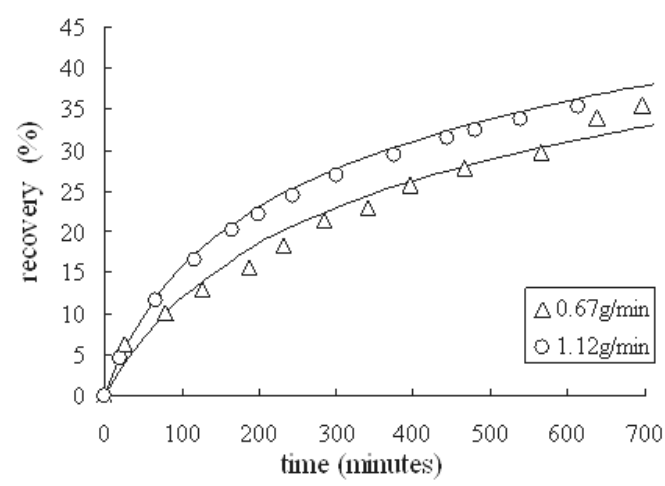

Figure 8: Recovery of pigments in supercritical $\left(\mathrm{CO}_{2}+\right.$ ethanol) extraction at 200 bar and $40{ }^{\circ} \mathrm{C}$ as a function of time, at two flow rates.— Model. 
The model can be represented by the following set of partial differential equations (PDE):

$$
\begin{aligned}
& \rho \mathrm{u} \frac{\partial \mathrm{y}}{\partial \mathrm{h}}+\rho \varepsilon \frac{\partial \mathrm{y}}{\partial \mathrm{t}}=\mathrm{R}\{\mathrm{x}, \mathrm{y}\} \\
& (1-\varepsilon) \rho_{\mathrm{s}} \frac{\partial \mathrm{x}}{\partial \mathrm{t}}=-\mathrm{R}\{\mathrm{x}, \mathrm{y}\}
\end{aligned}
$$

For the first system (internal mass transfer):

$$
\mathrm{R}\{\mathrm{x}, \mathrm{y}\}=\mathrm{A}_{\mathrm{p}} \mathrm{K}_{\mathrm{s}} \rho_{\mathrm{s}}\left(\mathrm{x}-\mathrm{x}^{*}\right)
$$

For the second system (external mass transfer):

$$
\mathrm{R}\{\mathrm{x}, \mathrm{y}\}=\rho \mathrm{A}_{\mathrm{p}} \mathrm{K}_{\mathrm{f}}(\mathrm{y} *-\mathrm{y})
$$

The initial and boundary equations are

$$
\begin{aligned}
& \mathrm{x}=\mathrm{x}_{0} \text { for } \mathrm{t}=0 \text {, any } \mathrm{h} \\
& \mathrm{y}=0 \text { for } \mathrm{h}=0 \text {, any } \mathrm{t}
\end{aligned}
$$

In these equations, $\mathrm{y}$ is the concentration in fluid phase, $x(\mathrm{~kg} / \mathrm{kg})$ is the concentration in solid phase (solute-free), $\mathrm{x}_{0}$ is the initial concentration of extractable pigments, $u(\mathrm{~m} / \mathrm{s})$ is the superficial velocity, $h(m)$ is the height of the extractor, $\rho$ is the solvent density $\left(\mathrm{kg} / \mathrm{m}^{3}\right), \varepsilon$ is the bed porosity, $\rho_{\mathrm{s}}$ $\left(\mathrm{kg} / \mathrm{m}^{3}\right)$ is the solid density, $\mathrm{y}^{*}(\mathrm{~kg} / \mathrm{kg})$ is the equilibrium concentration of pigment in the supercritical fluid, $x^{*}(\mathrm{~kg} / \mathrm{kg})$ is the equilibrium concentration in the solid at the solid-fluid interface, $A_{p} K_{f}\left(s^{-1}\right)$ is the overall external mass transfer coefficient and $A_{p} K_{s}\left(s^{-1}\right)$ is the overall internal mass transfer coefficient. $\mathrm{x}_{0}$ was determined asymptotically from the extraction curves when the supercritical extraction was only carried out with carbon dioxide and it was determined through an extraction of pigments from annatto seeds using chloroform when the supercritical solvent was carbon dioxide plus ethanol.

The set of two PDEs was transformed into one of
$2 n$ of ordinary differential equations (ODEs), corresponding to a division of the plug flow extractor in $n$ stages of perfect mixing. A Runge-Kutta method of the $4^{\text {th }}$ order was used to solve the $2 \mathrm{n}$ system of ODEs.

For the supercritical solvent without entrainer, for which only the internal mass transfer is considered, it is necessary to know how y relates to $\mathrm{x}^{*}$ (Reverchon, 1996). Another approach, which was used in the present work, is to consider $\mathrm{x}^{*}$ negligible, taking into account that the resistance to internal diffusion is much higher than the resistance to solvent diffusion (Sovovà, 1994a).

For the supercritical solvent with ethanol, for which an external mass transfer coefficient is determined, it is necessary to know $\mathrm{y}^{*}$. This concentration was determined extracting pigments previously separated from the seeds and mixed with glass beads, using $\mathrm{CO}_{2}$ plus ethanol at a pressure of 200 bar and a temperature of $40{ }^{\circ} \mathrm{C}$ (Nobre et al., 2003). It was found to vary during extraction (Fig. 7 ), and it was related to the corresponding concentration of the pigments in the seeds under these conditions of pressure and temperature, as shown in Eq. 7.

$$
\mathrm{y}^{*}\left[\mathrm{~g} / \mathrm{dm}^{3}\right]=0.0001 \exp \left(0.477 \mathrm{x}\left[\mathrm{g} / \mathrm{dm}^{3}\right]\right)
$$

In Table 1 the parameters used in the application of the models are shown and in Figure 8 the change in extraction as a function of time is shown for the two flow rates at the same pressure and temperature. The lines represent the calculated values from the plug flow model, assuming that the extraction is controlled by the solvent film around the seeds.

The values determined for the external mass transfer coefficients (Table 2) are comparable to the values known for several plant materials (Sovovà, 1994b). On the other hand, the internal mass transfer coefficients (Table 2) are also of the same order of magnitude as those indicated for extraction of solutes from the same plants. Moreover, the coefficients calculated in this work show a good agreement with those found in supercritical carbon dioxide extraction of $\beta$-carotene from Dunaliella salina (Mendes et al., 2000).

Table 1: Parameters used in the plug flow model.

\begin{tabular}{|l|r|}
\hline Concentration of extractable pigments in annatto seeds $\left(\mathrm{g} / \mathrm{dm}^{3}\right)$ & 13.7 \\
Density of the solid matrix $\left(\mathrm{g} / \mathrm{dm}^{3}\right)$ & 1145 \\
Volume of the extractor $\left(\mathrm{dm}^{3}\right)$ & 0.005 \\
Porosity & 0.65 \\
Internal diameter of the extractor $(\mathrm{mm})$ & 7.94 \\
Density of the supercritical fluid $\left(\mathrm{g} / \mathrm{dm}^{3}\right)$ & 840.5 \\
Particle diameter $(\mathrm{mm})$ & 3.5 \\
\hline
\end{tabular}


Table 2: Mass transfer coefficients for the supercritical extraction of pigments from the seeds of Bixa orellana at 200 bar and $40{ }^{\circ} \mathrm{C}$.

\begin{tabular}{|c|c|c|}
\hline $\begin{array}{c}\text { Flow rate } \\
(\mathbf{g} / \mathbf{m i n})\end{array}$ & $\begin{array}{c}\mathbf{A}_{\mathbf{p}} \mathbf{K}_{\mathbf{f}} \\
\left(\mathbf{m i n}^{-1}\right)\end{array}$ & $\begin{array}{c}\mathbf{A}_{\mathbf{p}} \mathbf{K}_{\mathbf{s}} \\
\left(\mathbf{m i n}^{-1}\right)\end{array}$ \\
\hline 0.67 & 0.49 & $3.0 \times 10^{-3}$ \\
\hline 1.12 & 0.63 & $3.0 \times 10^{-3}$ \\
\hline
\end{tabular}

\section{CONCLUSIONS}

The efficiency of supercritical carbon dioxide extraction of pigments from annatto seeds was low. When the flow rate of supercritical solvent increased, the recovery of pigments decreased, possibly due to resistance to mass transfer inside the seed pericarp. A high recovery of pigment was achieved when the mixed solvent $\left(\mathrm{CO}_{2}+\right.$ ethanol) was used. Moreover, this recovery didn't decrease with fluid flow rate and increased with pressure and temperature. The milling of the seeds had no effect on extraction.

An unsteady plug flow model was able to represent adequately the supercritical fluid extraction of the pigments from annatto seeds. When only $\mathrm{CO}_{2}$ was used an internal mass transfer coefficient was determined. On the other hand, when $\mathrm{CO}_{2}$ mixed with ethanol was used, extraction was controlled by solvent film. In this case, external mass transfer coefficients, which increased with flow rate, were calculated.

The calculated mass transfer coefficients compare well with those determined by other researchers for the supercritical fluid extraction of several solutes from plant materials.

\section{ACKNOWLEDGEMENT}

B. P. Nobre thanks FCT (Portugal) and F. L. P. Pessoa and E M. Queiroz thanks CAPES for the research grant.

\section{NOMENCLATURE}

$\begin{array}{llr}\mathrm{y} & \text { concentration in fluid phase } & (-) \\ \mathrm{x} & \text { concentration in solid phase } & \left(\mathrm{kg} / \mathrm{kg}_{\text {solute free }}\right) \\ \mathrm{x}_{0} & \begin{array}{l}\text { initial concentration of } \\ \text { extractable pigments }\end{array} & (-) \\ \mathrm{u} & \text { superficial velocity } & (\mathrm{m} / \mathrm{s}) \\ \mathrm{h}^{*} & \text { height of the extractor } & (\mathrm{m}) \\ \mathrm{y}^{*} & \begin{array}{l}\text { equilibrium concentration of } \\ \text { pigment in the supercritical }\end{array} & (\mathrm{kg} / \mathrm{kg}) \\ & \text { fluid }\end{array}$

$\mathrm{x}^{*} \quad$ equilibrium concentration in

$(\mathrm{kg} / \mathrm{kg})$ the solid at the solid-fluid interface

$\mathrm{A}_{\mathrm{p}} \mathrm{K}_{\mathrm{f}} \quad$ overall external mass transfer coefficient

$\mathrm{A}_{\mathrm{p}} \mathrm{K}_{\mathrm{s}} \quad$ overall internal mass transfer coefficient

\section{Greek Letters}

$\begin{array}{ll}\rho & \text { solvent density } \\ \varepsilon & \text { bed porosity } \\ \rho_{\mathrm{s}} & \text { solid density }\end{array}$

\section{REFERENCES}

Anderson, S.G., Muraleedharan, G.N., Chandra, A. and Morrison, E., Supercritical Fluid Carbon Dioxide Extraction of Annatto Seeds and Quantification of Trans-Bixin by High Pressure Liquid Chromatography, Phytochem. Anal., 8, 247 (1997).

Chao, R.R., Mulvaney, S.J., Sanson, D.R., Hsieh, F. and Tempesta, M.S., Supercritical $\mathrm{CO}_{2}$ Extraction of Annatto (Bixa orellana) Pigments and Some Characteristics of the Color Extracts. J. Food Sci., 56, No. 1, 80 (1991).

Degnan, A.J., Von Elbe, J.H. and Hartel, R.W., Extraction of Annatto Seed Pigments by Supercritical Carbon Dioxide, J. Food Sci., 56, No. 6, 1655 (1991).

Del Valle, J.M., Rivera, O., Mattea, M., Ruetsch, L., Daghero, J. and Flores, A., Supercritical $\mathrm{CO}_{2}$ Processing of Pretreated Rosehip Seeds: Effect of Process Scale on Oil Extraction Kinetics, J. Supercrit. Fluids, 31, 159 (2004).

McKeown, G.G. and Mark, E., The Composition of Oil-Soluble Annatto Food Colours, Journal of the AOAC, 45, No 3, 761 (1962).

Mendes, R.L., Coelho, J.P., Fernandes, H.L., Marrucho, I.J., Cabral, J.M.S., Novais, J.M. and Palavra, A.F., Applications of Supercritical Fluid Extraction to Microalgae and Plants, J. Chem. 
Tech. Biotechnol., 62, 53 (1995).

Mendes, R.L., Nobre, B.P. and Palavra, A.F., Supercritical $\mathrm{CO}_{2}$ Extraction of Beta-Carotene from Dunaliella salina, Proceedings of the $5^{\text {th }}$ International Symposium on Supercritical Fluids, Atlanta, CD (2000).

Mendes, R.L., Nobre, B.P., Cardoso, M.T., Pereira, A.P. and Palavra, A.F., Supercritical Carbon Dioxide Extraction of Compounds with Pharmaceutical Importance from Microalgae, Inorg. Chim. Acta, 356, 328 (2003).

Nobre, B.P., Queiroz, E.M., Pessoa, F.L.P., Coelho, J.P., Palavra, A.F. and Mendes, R.L., Solubility of Bixin and Bixin/Beta-Carotene Mixtures in Supercritical Carbon Dioxide (Proceedings of the $4^{\text {th }}$ International Symposium on High Pressure Technology and Chemical Engineering) Chemical Engineering Transactions, 2, 391 (2002).

Nobre, B.P., Queiroz, E.M., Pessoa, F.L.P., Coelho, J.P., Palavra A.F. and Mendes, R.L., Supercritical Carbon Dioxide Extraction of Bixin from Annatto Seeds, Proceedings of the $6^{\text {th }}$ International Symposium on Supercritical Fluids (Tome 1), p. 117 (2003).
Preston, H.D. and Rickard, M.D., Extraction and Chemistry of Annatto, Food Chem., 5, 47 (1980).

Reith, J.F. and Gielen, J.W., Properties of Bixin and Norbixin and the Composition of Annatto Extracts, J. Food Science, 36, 861 (1971).

Reverchon, E., Mathematical Modeling of Supercritical Extraction of Sage Oil, AIChE Journal, 42, No. 6, 1765 (1996).

Reverchon, E. and Marrone, C., Modeling and Simulation of the Supercritical $\mathrm{CO}_{2}$ Extraction of Vegetable Oils, J. Supercrit. Fluids, 19, 161 (2001).

Scotter, M.J., Thorpe, S.A., Reynolds, S.L., Wilson, L.A. and Strutt, P.R., Characterization of the Principal Colouring Components of Annatto Using High Performance Liquid Chromatography with Photodiode-Array Detection, Food Additives and Contaminants, 11, No. 3, 301 (1994).

Sovovà, H., Rate of the Vegetable Oil Extraction with Supercritical $\mathrm{CO}_{2}$ - I. Modeling of Extraction Curves, Chemical Engineering Science, 49, No. 3, 409 (1994a).

Sovovà, H., Modelling of the $\mathrm{CO}_{2}$ Extraction from Plant Materials, Proceedings of the $3^{\text {th }}$ International Symposium on Supercritical Fluids (Tome 2), p. 131 (1994b). 